\title{
PENERAPAN METODE ITERATIVE DICHOTOMIZER (ID3) UNTUK DIAGNOSA HAMA TANAMAN ANGGREK
}

\author{
Fathul Hafidh ${ }^{1)}$, Muhammad Edya Rosadi ${ }^{2}$, dan Rahmadi Agus ${ }^{3)}$ \\ ${ }^{1,2,3)}$ Fakultas Teknologi Informasi, UNISKA MAB Banjarmasin \\ e-mail: hafidh@,fti.uniska-bjm.ac.id ${ }^{1)}$, edya.rosadi@yahoo.com ${ }^{2)}$, radizqi@gmail.com $^{3)}$
}

\begin{abstract}
ABSTRAK
Tanaman anggrek merupakan salah satu komponen aspek estetika dan menjadi bagian dari kehidupan manusia. Sistem diagnosa untuk klasifikasi hama yang menyerang tanaman anggrek masih menggunakan model manual sehingga mengakibatkan kesulitan mengidentifikasi hama tanaman anggrek yang memiliki beragam gejala-gejala yang hampir sama. Seperti membedakan gejala kerusakan daun, akar dan bunga yang disebabkan oleh hama. ID3 mampu menghasilkan sebuah pohon keputusan dari suatu kumpulan data yang sangat banyak. Pohon keputusan ini bisa dijadikan sebagai acuan diagnosa hama pada tanaman anggrek. Pada penelitian ini klasifikasi hama tanaman anggrek dilakukan dengan metode ID3 dengan tingkat performa akurasi sebesar $78.06 \%$.
\end{abstract}

Kata Kunci: Anggrek, ID3, Pohon Keputusan.

\begin{abstract}
Orchid plants is one component of the aesthetic aspect and become a part of human life. Diagnostics system for classification orchid pests were attack plants still using the manual model, it's result difficulty identifying pests orchid that has a variety of symptoms are almost the same. As to distinguish the symptoms of damage to the leaves, roots and flowers caused by pests. ID 3 able to generate a decision tree of large data sets. This decision tree can be used as a reference for the diagnosis of pests on orchids. In this research, pest classification of orchids do with ID3 method with the highest level of performance accuracy is $78.06 \%$.
\end{abstract}

Kata Kunci: Decision Tree, ID3, Orchid.

\section{PENDAHULUAN}

$\mathrm{B}$ agi para pecinta tanaman hias, keberhasilan dalam membudidayakan tanaman tentu mempunyai nilai kepuasan yang sangat tingi. Begitu pula bagi penggemar tanaman anggrek, memiliki tanaman yang sehat dan hijau berbunga adalah kebanggan. Akan tetapi anggrek juga tidak luput dari hama, pengendalian hama merupakan aspek budi daya anggrek yang tidak kalah pentingnya. Hama adalah hewan-hewan kecil perusak seperti serangga, tungau, ulat, keong dan sebagainya. Hewan ini merusak tanaman dengan menghisap cairan atau memakan bagian dari tanaman.

Salah satu alternatif pemecahan masalah tersebut adalah mengembang-kan suatu program komputer yang dapat mampu mengklasifikasikan hama tanaman apa yang menyerang tanaman anggrek. Hasil dari sistem ini adalah klasifikasi serangan hama yang menyerang tanaman anggrek dengan cara memasukkan data gejala-gejala fisik pada tanaman dari sampel yang terdahulu.

Data mining adalah ekstraksi pola yang menarik dari data yang besar, dikatakan menarik apabila pola tersebut tidak sepele, implisit, dan tidak diketahui sebelumnya. ID3 adalah salah satu metode klasifikasi dalam data mining yang dapat menghasilkan suatu pohon keputusan dari suatu kumpulan data sehingga diketahui faktor-faktor yang paling mempengaruhi dalam suatu data.

ID3 yang diterapkan pada data hama pada tanaman anggrek akan menghasilkan tree yang bisa digunakan untuk membuat diagnosa terhadap hama yang menyerang tanaman anggrek. 


\section{RUMUSAN MASALAH}

Berdasarkan latar belakang yang sudah dipaparkan diatas, maka rumusan masalahnya adalah bagaimana menghasilkan suatu tree dengan akurasi yang baik dengan ID3 yang diterapkan pada data hama tanaman anggrek.

\section{III.TUJUAN PENELITIAN}

Penelitian ini bertujuan untuk meningkatkan akurasi dari klasifikasi ID3 yang diterapkan pada data hama tanaman anggrek.

\section{IV.TARGET LUARAN DAN MANFAAT PENELITIAN}

Hasil penelitian ini diharapkan mampu memberikan manfaat bagi masyarakat untuk dapat melakukan tindakan-tindakan preventif kepada tanaman anggrek yang terserang hama.

Dalam bidang keilmuan penelitian ini diharapkan berkontribusi pada perkembangan keilmuan tentang data mining pada umumnya dan pada klasifikasi ID3 pada khususnya.

\section{METODE PENELITIAN}

Metode penelitian yang dilakukan adalah metode penelitian eksperimen, dengan tahapan penelitian seperti berikut:

a. Pengumpulan Data (Data Gathering)

Data yang digunakan adalah data dari Dinas Kehutanan Provinsi Kalim Banjarbaru. Data hama pada tanaman anggrek tersebut kemudian di input ke dalam software pengolah angka.

b. Pengolahan Data Awal (Data Pre-processing)

Data dikonversi menjadi binominal agar dapat diproses dengan model ID3.

c. Desain Eksperimen dan Pengujian Metode (Method Test and Experiment)

Eksperimen dilakukan dengan menerapkan ID3 pada data yang sudah melalui pre-processing dan kemudian diuji tingkat akurasi klasifikasinya dengan metode X-validation, untuk mendapatkan akurasi dari penerapan metode tersebut.

d. Analisa Hasil Eksperimen

Pengukuran tingkat akurasi di-lakukan dengan menghitung Precision dan Recall dari tree yang dihasilkan untuk dianalisa peningkatan akurasinya. Semakin tinggi nilai akurasinya menyatakan semakin baiknya klasifikasi dan mendekati dengan solusi ideal.

\section{A. Hasil Penelitian}

\section{ANALISA HASIL DAN PEMBAHASAN}

a. Penelitian dilakukan dengan menginput data hama pada tanaman anggrek ke dalam software pengolah angka, kemudian data tersebut diimport ke dalam Rapidminer. Dalam Rapidminer terdapat dua (2) proses, yang pertama adalah penerapan metode ID3 hingga menghasilkan Tree (Pohon Keputusan) dan yang diukur performanya dengan metode X-validation, untuk mendapatkan tingkat akurasi dari penerapan metode tersebut.

b. Dari data yang telah dibuat, kemudian diolah dengan metode ID3 menghasilkan tree yang akan diukur performanya terhadap data berikut gambar tree dari hasil permodelan ID3 terhadap data hama tanaman anggrek.

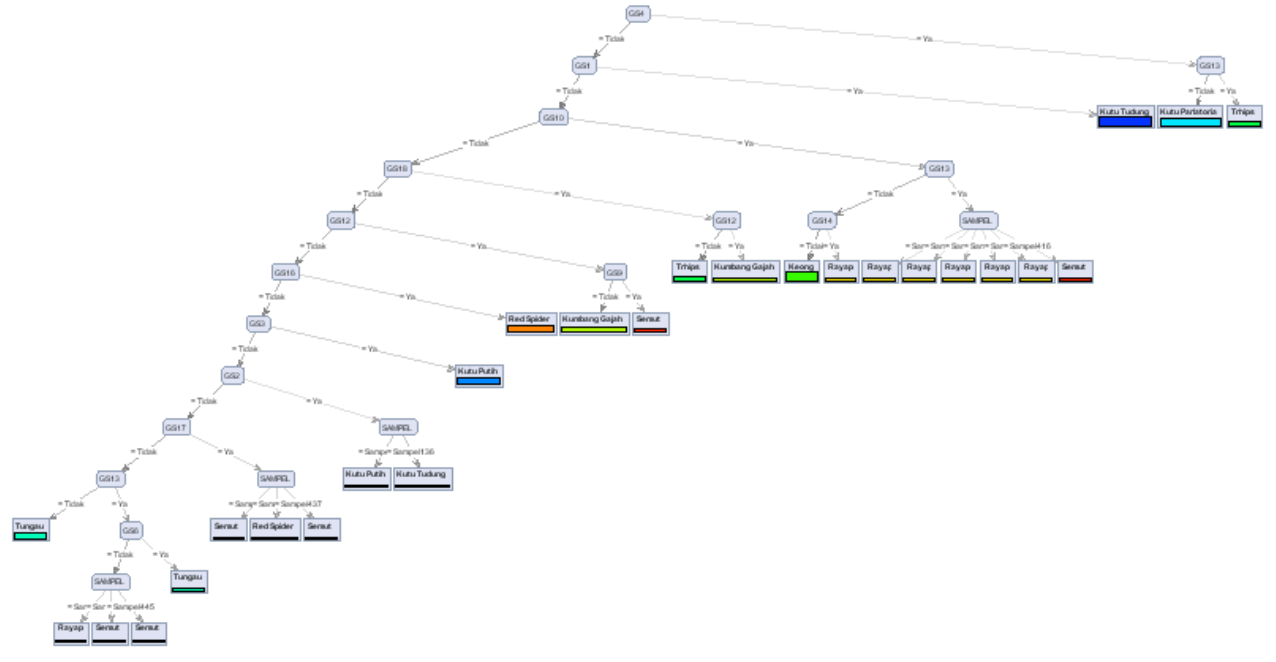

Gambar 1 Tree Hasil ID3

\section{B. Pembahasan}

Data hama penyakit pada tanaman anggrek diproses dengan permodelan ID3 menghasilkan tree, performa akurasi, precision dan recall. 
Tree yang dihasilkan menunjuk-kan daun bewarna kuning berbintik coklat memiliki pengaruh paling utama dimana jika daun bewarna kuning berbintik coklat dan umbi semu rusak maka hama Thrips yang menyerang anggrek tersebut. Sedangkan bila disertai daun berwarna kuning maka hama yang menyerang kutu tudung.

Berikut hasil performa aksurasi dari metode ID3 pada diagnosa hama tanaman anggrek:

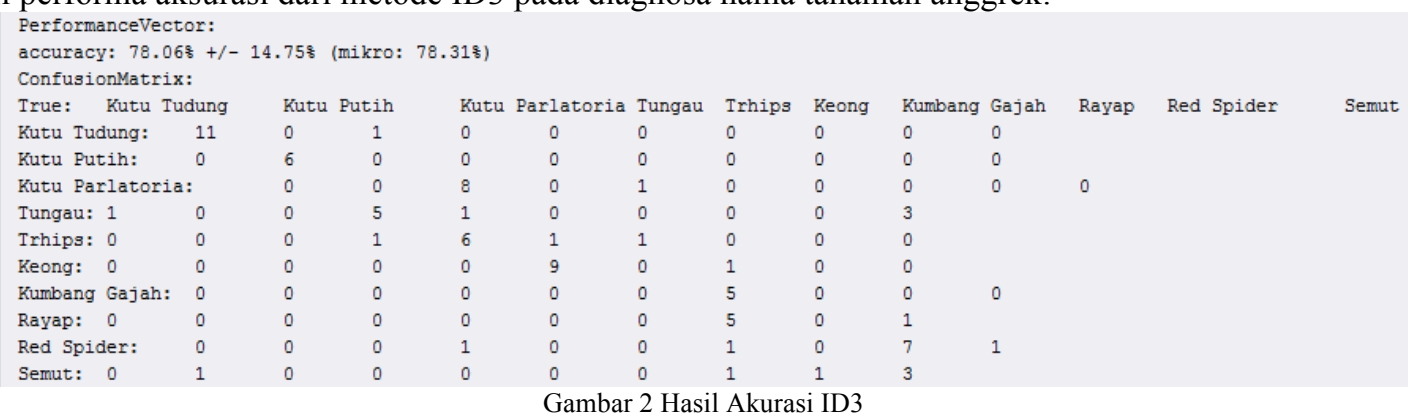

Dari gambar 5.2 dapat dilihat performa akurasi ID3 pada data hama tanaman anggrek dari 78.06\%.

\section{A. Kesimpulan}

\section{PENUTUP}

Hama pada tanaman anggrek dapat diklasifikasikan dengan metode ID3 dan menjadi sebuah pohon keputusan dengan menerapkan metode ID3. Selain pohon keputusan yang dapat menjadi sebuah acuan dalam penentuan hama pada tanaman anggrek, metode ID3 juga memiliki tingkat performa akurasi yang baik yaitu sebesar 78.06\%. Hasil penelitian ini dapat dimanfaatkan menjadi metode untuk menentukan hama yang ada pada tanaman anggrek, sehingga memudahkan proses penanggulangan penyakit pada tanaman anggrek. 


\section{DAFTAR PUSTAKA}

[1] A. D. T. Larose, Data Mining Methods and Models, Connecticut: Wiley-Interscience, 2007.

[2] B. A. A. M. Ningsih, Merancang dan Mengimplementasikan Algoritma ID3 pada Sistem Pendeteksi Penyakit Tanaman Karet, Salatiga: Universitas Kristen Satya Wacana, 2012.

[3] C. N. A. Kartika, Penerapan Teknik Data Mining Menggunakan Algoritma Iterative Dichotomizer (ID3) untuk Menentukan Potensi Siswa dalam Dunia Kerja Berdasarkan Kecerdasan Emosi, Semarang: Universitas Dian Nuswantoro, 2014.

[4] D. R. A. Giovani, Sistem Pendukung Keputusan Prediksi Kecepatan Studi Mahasiswa Menggunakan Metode ID3, Yogyakarta: Universitas Atmajaya Yogyakarta, 2011.

[5] E. D. I. L. W. Gunawan, budi daya anggrek, jakarta: penebar swadaya, 2007.

[6] F. r. Novianti, "penerapan teorema bayes pada sistem pakar untuk dianosa penyakit hewan ternak sapi," 2011.

[7] G. D. Hand, "Data Mining Concepts and Techniques Second Edition," University of Illinois, p. 2, 2006.

[8] H. I. H. Iswanto, Petunjuk perawatan anggrek, Jakarta: ArgoMedia Pustaka, 2007.

[9] I. R. AgroMedia, Cara tepat merawat anggrek, Jakarta: PT AgroMedia Pustaka, 2008.

[10] J. Dewi, Yanti, "Perancangan Sistem Pakar Penyakit Utama Kelapa Sawit," Universitas Sumatera Utara, p. 1, 2010.

[11] K. S. Kusumadewi, Artifical Intelligene (Teknik dan Aplikasinya), Yogyakarta: Graha Ilmu, 2003. 